\title{
Structural and the Optical Properties of Graphene Prepared by Electrochemical Exfoliation Technique
}

\author{
Raneen Imad Jibrael ${ }^{1}$ and Mustafa K. A. Mohammed \\ Department of Applied Science, University of Technology, Baghdad-Iraq. \\ ${ }^{1}$ E-mail: ranenalkess@yahoo.com.
}

\begin{abstract}
In this research, graphene suspension was prepared by electrochemical exfoliation of graphite electrodes immersed in aqueous solution which contains sulfuric acid, nitric acid and distilled water $\left(\mathrm{H}_{2} \mathrm{SO}_{4} / \mathrm{HNO}_{3} / \mathrm{H}_{2} \mathrm{O}\right)$. DC biases of $10 \mathrm{~V}$ have been applied and the graphene foam was deposited on glass slide. The structural and optical properties of graphene was characterized via X-ray diffraction (XRD), scanning electron microscope (SEM), energy dispersive spectroscopy (EDS), optical microscopy (OP) and Uv-Vis spectroscopy respectively. The XRD pattern shows crystalline structure of graphene with sharp peak at $26.59^{\circ}$ corresponds to an interlayer distance of $0.334 \mathrm{~nm}$ of (002) orientation which matching with the interlayer distance of normal graphite. The SEM of graphene was showed that thin layered graphene structures with wrinkled shapes. The compositions of graphene consist of carbon and oxygen with atomic percentages $82.75 \%$ and $12.01 \%$, respectively. The absorbance spectra using UV-VIS was exibited the graphene suspension and graphene film have two transitions included $\pi-\pi^{*}$ and $n-\pi^{*}$ respectively.
\end{abstract}

Keywords: Graphene, electrochemical exfoliation, aqueous solution, graphite electrode.

\section{Introduction}

Graphene is a single atom-thick plane of carbon atoms arranged in a honeycomb lattice, is the conceptual building block for many carbon allotropes, from three dimensional graphite (a stack of graphene sheets), to onedimensional carbon nanotubes (seamless graphene cylinders), to zero-dimensional buckyballs (closed graphitic cages $)^{[1]}$. Graphene is a wonder material with many superlatives to its name. It is the thinnest material in the universe and the strongest ever measured. Its charge carriers exhibit giant intrinsic mobility, have the smallest effective mass (it is zero) and can travel micrometerlong distances without scattering at room temperature. Graphene can sustain current densities 6 orders higher than copper, shows record thermal conductivity and stiffness ${ }^{[2]}$. In recent years, graphene has been produced by many kinds of physical and chemical methods. Among them, graphene derived from chemical oxidation-reduction method exhibits extensive defects, while graphene prepared by CVD, liquid phase production, and mechanical cleavage of graphite presents no defects ${ }^{[3]}$. The electrochemical method has the advantages of being single-step, easy to operate, environmentally friendly (if using ionic liquid electrolytes or aqueous surfactants) and operates at ambient conditions. Highly controllable flakes can be formed without the need for volatile solvents or reducing agents. Recently, electrochemical methods have been used by a number of research groups to produce graphene in milligram and gram quantities ${ }^{[4]}$ such as Prashant Tripathi et al. prepared high-quality graphene by exfoliation of graphite electrode in alkaline solution as electrolyte ${ }^{[5]}$, ChingYuan $\mathrm{Su}$ et al. synthesized high-quality thin graphene films by exfoliation of graphite in many different electrolytes including $(\mathrm{HBr}$, $\mathrm{HCl}, \mathrm{HNO}_{3}$, and $\left.\mathrm{H}_{2} \mathrm{SO}_{4}\right)^{[6]}$ also Khaled Parvez et al. prepared of graphene via exfoliation of graphite flakes in aqueous solutions $\left(\left(\mathrm{NH}_{4}\right)_{2} \mathrm{SO}_{4}, \mathrm{H}_{2} \mathrm{O}\right)^{[7]}$. The aims of this research are preparing of graphene suspension and depositing on glass slide to study optical and structural properties.

\section{Experimental work}

In this work, graphite rods were used as electrodes (i.e. anode and cathode) with dimensions ( $3 \mathrm{~cm} \times 3.16 \mathrm{~mm}$ ) and weight of $0.47 \mathrm{gm}$ before exfoliation as shown in Fig.(2a). In addition, the separation distance between graphite electrodes was fixed to be 
$4 \mathrm{~cm}$, these electrodes were immersed in aqueous electrolyte consist of sulfuric acid $\mathrm{H}_{2} \mathrm{SO}_{4}(0.69 \mathrm{gm})$ and nitric acid $\mathrm{HNO}_{3}$ $(0.19 \mathrm{gm})$ of $1: 3$ volume ratio added to 1000 $\mathrm{ml}$ of de-ionized water to make $\mathrm{pH}$ solution value around 3 , at room temperature. The process of electrochemical exfoliation was conducted by applying constant current (DC) bias on the graphite electrode, the bias of 1 Volt was first applied of the graphite electrode for 5 minute, then by increasing the bias to 10 Volt for other 5 minute. The elementary low bias helps to moistening the sample, before implementation a high bias of 10 Volt, graphite still yet as a one piece. When applying the high bias to the graphite, it will quickly separate into small pieces and spread in solution surface as shown in Fig.(2c). During the exfoliation there are two types of graphitic flakes formed; one gets sediment at the bottom which consists of thick graphitic pieces. The second type of graphitic sample floats on the surface of electrolyte. These flakes are nearly transparent and have been found to consist of few layer graphene (FLG). After preparation of graphene, the glass slide was washed with distilled water to remove any oil or dust that might be on the substrate surface and then placed in a clean beaker containing HCL acid for $5 \mathrm{~min}$; finally it is put in ultrasonic bath with distilled water for 10 min then dry. A pipette was used to deposit the graphene foam Fig.(2d) on the glass surface. Afterwards, sonication of the glass slide by ultrasonic cleaner with power 50 watt

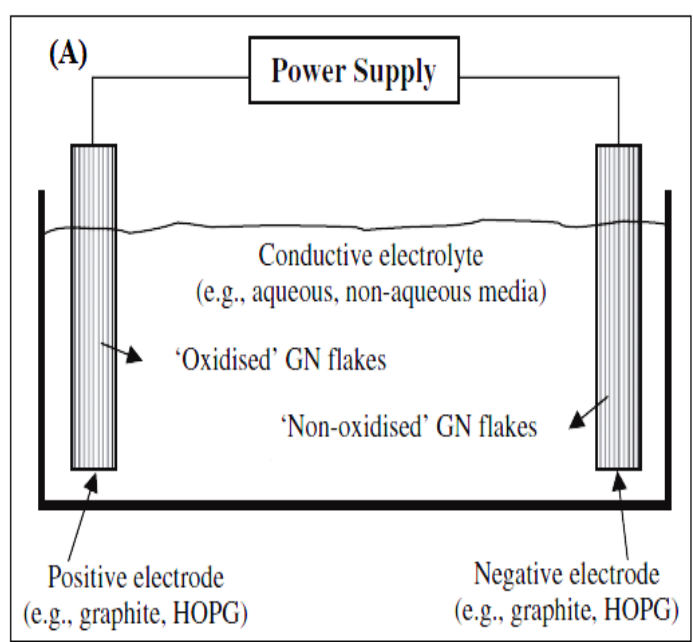

to insure that the film homogenous and smooth. Finally, the graphene film was heated at $200^{\circ} \mathrm{C}$ for 120 minutes under vacuum.

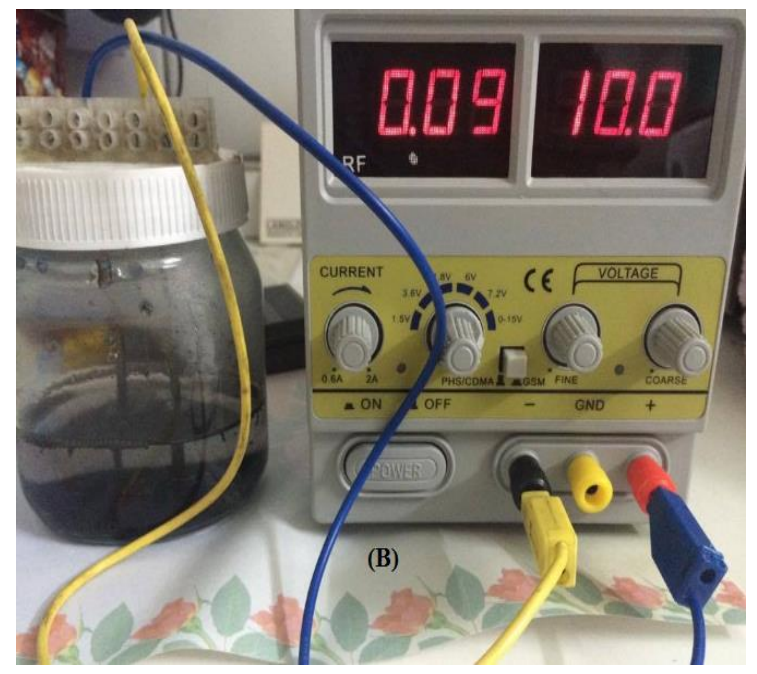

Fig.(1): a) Schematic illustration of electrochemical exfoliation process. b) expermiental setup of this work. 


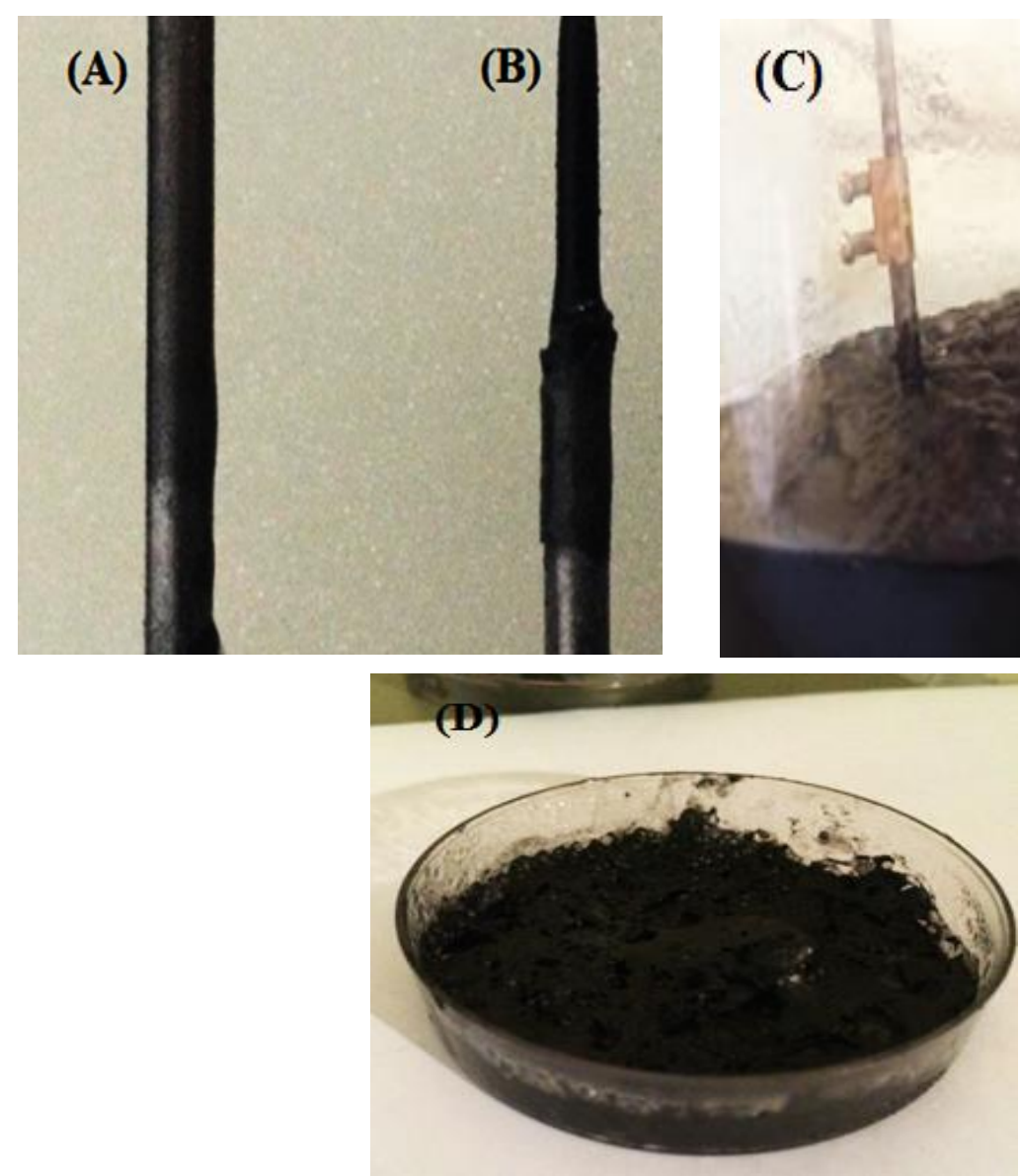

Fig.(2): Graphite electrodes a) before exfoliation and b) after exfoliation. c) the dispersed graphene sheets in aqueous solution after applying +10 V for 50 min. d) foam of graphene.

\section{Material characterization}

Structural properties were measured by X-ray Diffraction (XRD) according to the Joint Committee on Powder Diffraction Standards (JCPDS) card, using Shimadzu XRD-7000 X-ray diffractometer using $\mathrm{CuK} \alpha$ $\left(\lambda=1.54050 \mathrm{~A}^{\circ}\right)$ irradiation operated at $40 \mathrm{kV}$ and $30 \mathrm{~mA}$. In addition, scanning electron microscopy (SEM) (model the VEGA Easy Probe) and Energy-dispersive $\mathrm{x}$-ray spectroscopy (EDS) was used for the quantitative elemental analysis of the chemical characterization of graphene (Inspect S; produced by FEI Company, Eindhoven, The Netherlands). The transmittance optical microcopy (model olympus bx 60) was used to known the topography and structural information at 1000x. Optical properties measured by UV-V is single beam spectrophotometer (model Lambda 750, Perkin Elmer) was used to record the optical spectrum of the graphene film within the wavelength ranging from $200 \mathrm{~nm}$ to $400 \mathrm{~nm}$.

\section{Results and Discussion 4.1 X-ray Diffraction}

Fig.(3) shows the natural graphite (graphite electrodes) before exfoliation process, which is polycrystalline in nature and has a intense and sharp peak at $2 \theta$ equal to $26.6^{\circ}$ corresponding to an interlayer distance of $0.334 \mathrm{~nm}$ along the (002) orientation calculated using Bragg's law as in :

$$
2 d \sin \theta=n \lambda
$$
(1)(Bragg's law)

here $\lambda$ is the wavelength of X-ray is beam $(0.154606 \mathrm{~nm}), \theta$ is the scattering angle, $n$ is order of diffraction peak, $d$ is interplane distance.

This is consistent with the layer spacing of normal graphite according to JCPDS standard card (230064), which has interlayer distance equal to $0.335 \mathrm{~nm}$. Also has diffraction peak at $2 \theta$ of $54.6^{\circ}$ corresponding to the interlayer distance of $0.16 \mathrm{~nm}$ along the (004) orientation. 


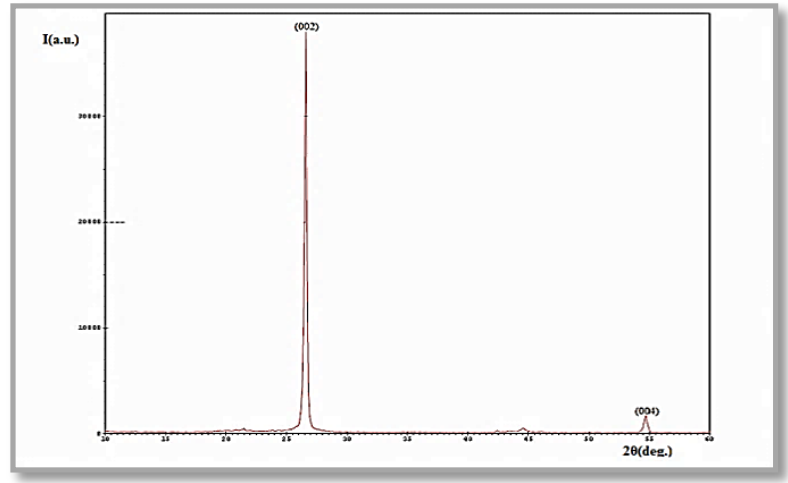

Fig.(3) : XRD pattern of the graphite electrode.

Fig.(4) show the XRD results of graphene film deposited on glass slide, the XRD pattern exhibited a sharp diffraction peak at $2 \theta=26.59$ degree, corresponds to an interlayer distance of $0.334 \mathrm{~nm}$ for (002) orientation estimated by Eq1. which is consistent with the layer spacing of JCPDS card (230064), which has interlayer distance equal to $0.335 \mathrm{~nm}$. While the orientation of (004) was vanished due to annealing process make the structure of graphene more crystalinity toward single crystalline. The crystallite size of graphene film has been measured by applying Scherrer's eq. as shown below ${ }^{[8]}$ :

$$
L=\frac{k \lambda}{B \cos \theta}
$$

where $L$ is crystallite size (nm) equal to $15.34 \mathrm{~nm}, B$ is FWHM and $k$ is a constant $(k=0.89)$. Also from XRD pattern there are two small peaks at $2 \theta=19.6$ and $2 \theta=21.95$ corresponding to the $d$-spacing of $0.45 \mathrm{~nm}$ and $0.4 \mathrm{~nm}$ respectively along the (002) orientation. The slightly lower $2 \theta$ angle of graphene with large d-spacing compared to graphite suggests that, graphene contains only a small amount of functional groups.

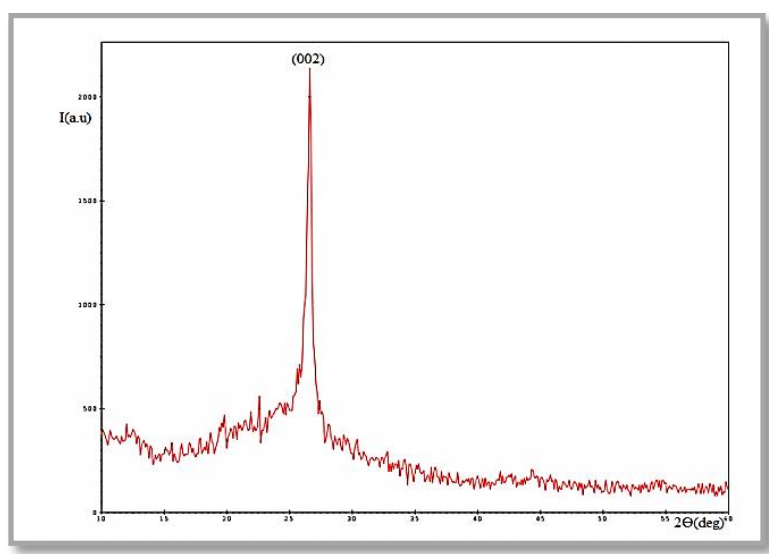

Fig.(4): XRD pattern of the graphene film.

\subsection{Scanning Electron Microscopy (SEM)}

The surface of the graphene film was analyzed with SEM, and the image is represented in Fig. (5) at scale bars $=5 \mu \mathrm{m}$. The SEM image of graphene shows a typical worm-like shape with thin layered graphene structures. The stacked graphene laminates appear wrinkled, which is something typical of graphene sheets as confirmed in the literature ${ }^{[4]}$. Revealing a crumpled and rippled structure which was the result of deformation upon the exfoliation and restacking processes. Corrugation and scrolling suggested the intrinsic nature of graphene, because the 2D membrane structure would be thermodynamically stable via blending ${ }^{[9]}$.

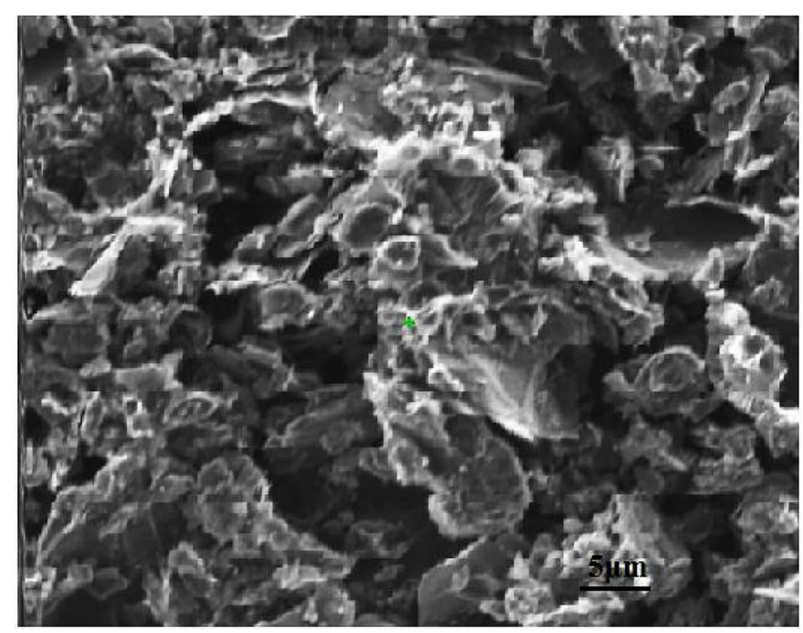

Fig.(5): SEM images of graphene film prepared by electrochemical method at Scale bars $=5 \mu m$.

\subsection{Energy Dispersion Spectroscopy (EDS)}

Fig.(6) shows the elemental composition of graphene in terms of atomic percentages are as following: C: $82.75 \%$ and $\mathrm{O}: 12.01 \%$, upon applied of DC potential $(\mathrm{E}=+10 \mathrm{~V})$, at the anodic graphite rod, water molecules easily undergo oxidation to yield free radicals which, in turn lead to the formation of oxygen containing functional groups, on the graphene sheets, These sheets are exfoliated from the anodic rod, upon action of water and potential, which act cumulatively to remove layers of graphene that collapse into the solution. Thus the graphene generated in the ionic liquid medium also has an oxidized graphene component. 


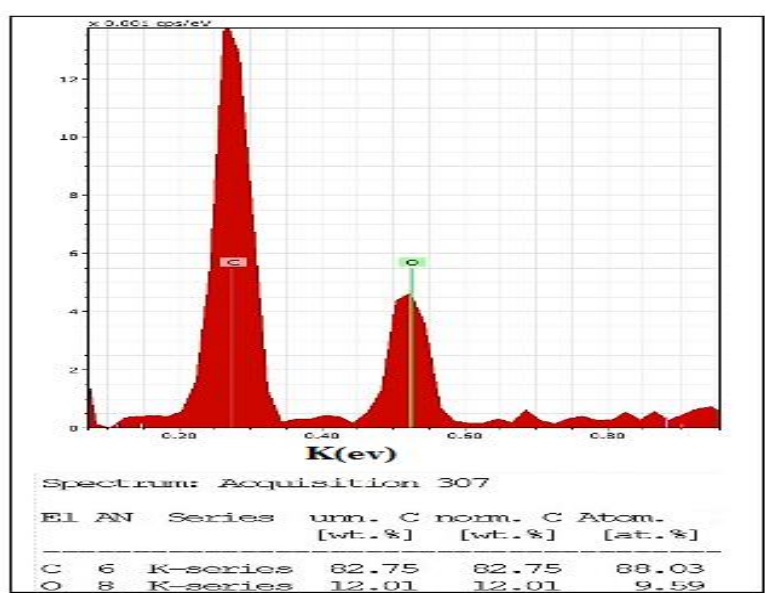

Fig.(6): Energy dispersive spectroscopy plot of graphene film.

\section{4- Optical Microscopy (OM)}

Fig.(7a and b) shows optical microscope images of graphene film prepared by electrochemical method at $500 \mathrm{X}$ and $1000 \mathrm{X}$ magnification. The color of the graphene film changes depending on its thickness. From these figures we can see there are impurities with the graphene film due to present residual ions from aqueous solution and the graphene film not uniform above the glass slide.

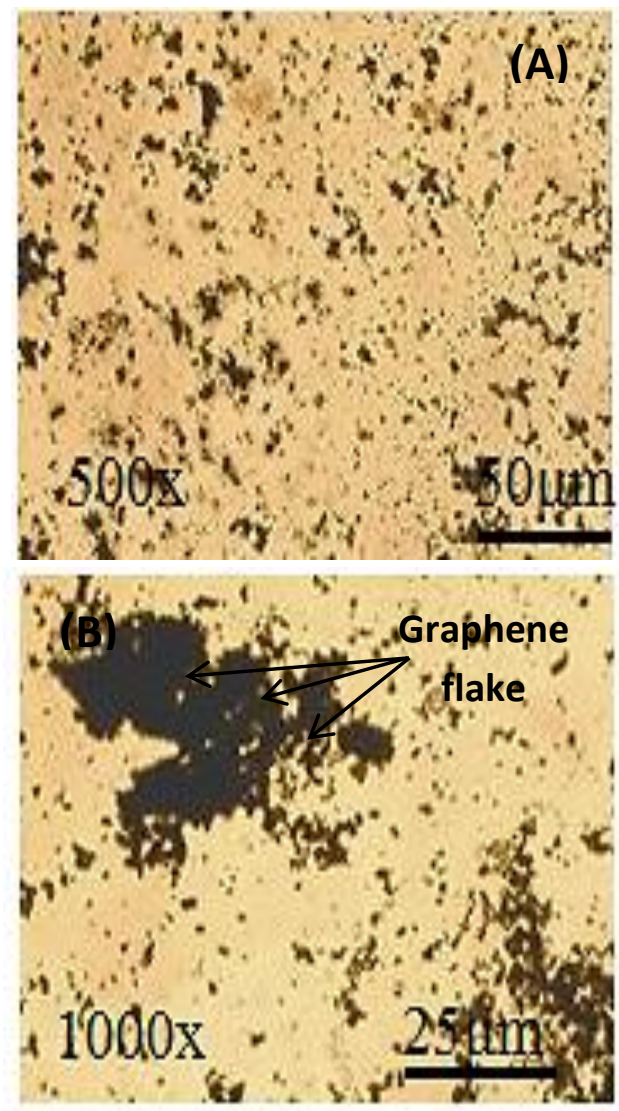

Fig.(7): Optical microscope images of graphene film magnified at a) 500x and b) $1000 x$.

\subsection{UV-Vis Spectroscopy}

Uv-visible absorption spectra of prepared graphene suspensions have been shown in Fig.(8a and b), In Fig.(8a), maximum absorbance was obtained at about $230 \mathrm{~nm}$, corresponding to $\pi-\pi^{*}$ transition of aromatic $\mathrm{C}=\mathrm{C}$ bonds, and shoulder peak at $\sim 295 \mathrm{~nm}$ represented $n-\pi^{*}$ transitions of $\mathrm{C}-\mathrm{C}$ bonds. The spectrum obtained is in agreement with the previously reported results ${ }^{[10-11]}$. Fig.(8b) shows the Uv-Vis absorption spectrum of graphene film deposited on glass slide, the maximum absorbance peak was obtained at about $225 \mathrm{~nm}$, corresponding to $\pi-\pi^{*}$ transition of aromatic $\mathrm{C}=\mathrm{C}$ bonds, and another peak at $290 \mathrm{~nm}$ of $\mathrm{n}-\pi^{*}$ transitions of C-C bonds. The Uv-Vis spectra of graphene suspension showed a blue shift due to of the presence of water content in the ionic liquid which makes the viscosity of the electrolyte reduced.
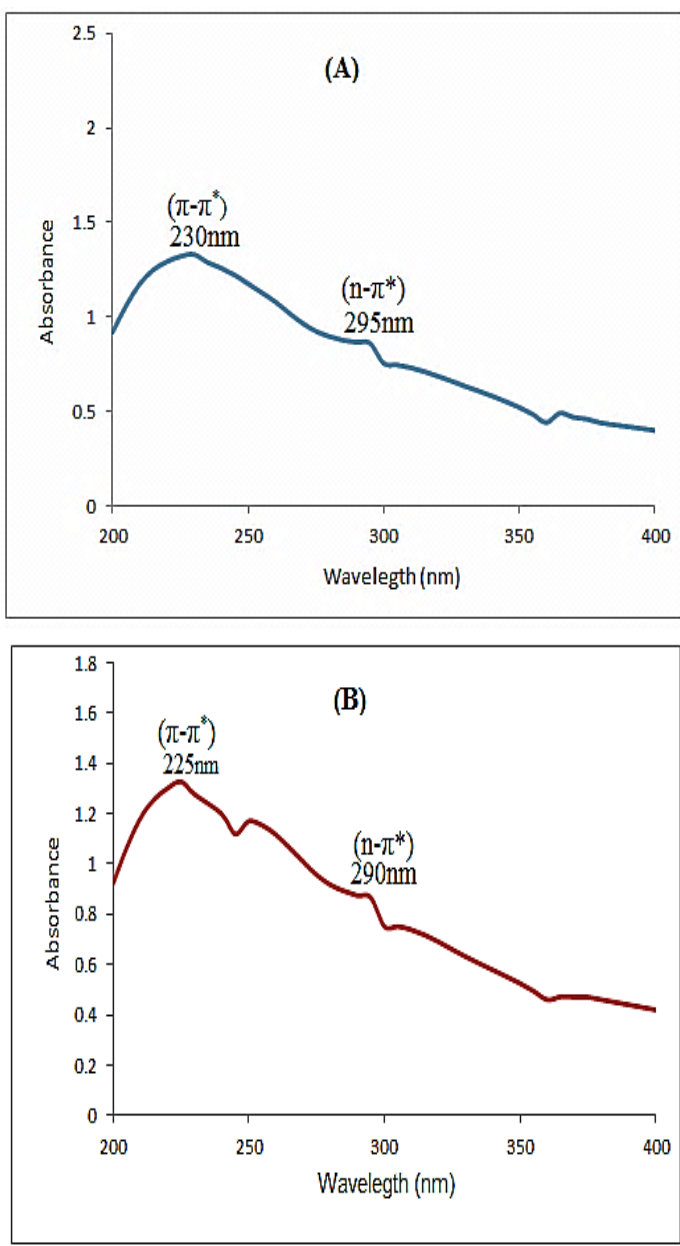

Fig.(8): Plot of absorbance vs. wavelength for a) graphene suspension and b) graphene film. 


\section{Conclusions}

In conclusion, we have successfully prepared good quality graphene suspension by electrochemical exfoliation of graphite employing aqueous electrolyte. This technique is a one-step simple procedure to attain the objective and has the potential to be scaled up easily at relatively low costs. The exfoliated graphene sheets exhibit crumpled morphology has been characterized by optical microscopy and scanning electron microscopy, while the energy dispersive spectroscopy and X-ray diffraction showed that the structure of graphene film has small amount of defect and a few oxygen concentration. The characterization of optical properties of graphene has been shown two main transitions for graphene which agreement with the previously reported.

\section{References}

[1] Fuhrer, Michael S. Lau, Chun Ning MacDonald and Allan H, "Graphene: Materially Better Carbon", MRS Bulletin, 35, 289-295, 2010.

[2] A. K. Geim, "Graphene: Status and Prospects", Science, 324, (5934), 15301534, 2009.

[3] Fu, Changjing Zhao, Guogang Zhang, HaijunLi and Shuang, "Evaluation and Characterization of Reduced Graphene Oxide Nanosheets as Anode Materials for Lithium-Ion Batteries", Int. J. Electrochem. Sci, 8, 6269-6280, 2013.

[4] C.T. Low, J. Walsh, F.C. Chakrabarti, M.H. Hashim, M.A. and Hussain M.A, "Electrochemical approaches to the production of graphene flakes and their potential applications", Carbon, 54, 1-21, 2013.

[5] Prashant Tripathi, Ch. Ravi Prakash Patel, M. A. Shazand O. N. Srivastava, "Synthesis of High-Quality Graphene through Electrochemical Exfoliation of Graphite in Alkaline Electrolyte”, RSC Adv., 3, 1174511750, (2013).

[6] Ching-Yuan Su, Ang-Yu Lu, Yanping Xu, Fu-Rong Chen,Andrei N. Khlobystov, and Lain-Jong Li, "High-Quality Thin
Graphene Films from Fast Electrochemical Exfoliation" ACS Nano, 5, 2332-2339, 2011.

[7] Khaled Parvez, Zhong-Shuai Wu, Rongjin Li, Xianjie Liu, Robert Graf, Xinliang Feng and Klaus Müllen, "Exfoliation of Graphite into Graphene in Aqueous Solutions of Inorganic Salts" Journal of the American Chemical Society, 163, 6083-6091, 2014.

[8] Seung Hun Huh, "Thermal Reduction of Graphene Oxide" Physics and Applications of Graphene Experiments, 73-90, 2011.

[9] Novoselov KS, Jiang Z, Zhang Y, Morozov SV, Stormer HL, Zeitler U, Maan JC, Boebinger GS, Kim P and Geim AK., "Room-temperature quantum Hall effect in graphene" Science., 315(5817): 1379, 2007.

[10] Sumit Saxena, Trevor A. Tyson, Shobha Shukla, Ezana Negusse, Haiyan Chen, and Jianming Bai, "Investigation of structural and electronic properties of graphene oxide" Applied Physics Letters, 99, 20112014, 2011.

[11] Leila Shahriary, and Anjaali A. Athawale, "Graphene Oxide Synthesized by using Modified Hummers Approach" nternational Journal of Renewable Energy and Environmental Engineering, 2, 58-63, (2014).

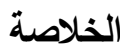

$$
\begin{aligned}
& \text { في هذا البحث، تم تحضير عالق الكرافين بواسطة } \\
& \text { التقثير الكهروكيمباوية لأقطاب الجرافيت المغمورة في محلول } \\
& \text { مائي لحامض الكبريتيك وحامض النتريك وماء مقطر } \\
& \text { ( } \left.\mathrm{H}_{2} \mathrm{SO}_{4} / \mathrm{HNO}_{3} / \mathrm{H}_{2} \mathrm{O}\right) \\
& \text { انحياز DC بقيمة } 10 \text { و تم نرسيب رغوة الكرافين على } \\
& \text { لوح الزجاج. الخصائص التركيبية والبصرية للكرافين شخصت } \\
& \text { عن طريق حيود الاشعة السينية(XRD) والمجهر الالكتروني } \\
& \text { الماسح (SEM) ومطياف المشتت للطاقة (EDS) والمجهر } \\
& \text { الضوئي(OP) ومطياف الضوئي بالمنطقة الفوق البنفسجية } \\
& \text { والمرئية(Uv-Vis) على التوالي. اظهر نموذج حيود الاشعة }
\end{aligned}
$$


السينية للتركيب البلوري للكرافين قمة حادة عند $26.59^{\circ}$

والتي تقابل مسافة بين المستوبات تساوي 0.334 بتجاه

(002) تتوافق مع المسافة بين المستويات للجرافيت الطبيعي.

اظهر فحص SEM لتراكيب الكرافين بانه متكون من طبقات

قليلة مع وجود اثكال متجعدة. البنية التركيبية للكرافين ثتكون

من كاربون واكسجين بنسب ذرية \% 12.01 و 82.75 \%

Uv-Vis على التوالي. اظهرت اطياف الامتصاص بواسطة

لعالق الكرافين وغشاء الكرافين يمتلك انتقالين تضمنت

$$
\text { و }
$$

كلمات مفتاحية: كرافين، تقتير كهروكيميائية، محلول مائي،

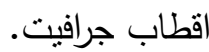

